\title{
PERANAN CAMAT DAN KOMUNIKASI PEMERINTAHAN TERHADAP PERENCANAAN PEMBANGUNAN DI KECAMATAN MALUA KABUPATEN ENREKANG
}

Oleh

\begin{abstract}
Ahmad Mustanir ${ }^{1)}$, Muhammad Rohady Ramadhan ${ }^{2)}$, M Rais Rahmat Razak ${ }^{3)}$, Lukman ${ }^{4)}$, Sapri ${ }^{5)}$ Takhrim $^{6}$
\end{abstract}

1) 2) 3) 4) 5) Dosen Universitas Muhammadiyah Rappang

6) Mahasiswa Universitas Muhammadiyah Rappang

E-mail: ahmadmustanir74@gmail.com

\begin{abstract}
Abstrak
Penelitian ini bertujuan untuk mengetahui Peranan Camat dan Komunikasi Pemerintahan terhadap Perencanaan Pembangunan di Kecamatan Malua Kabupaten Enrekang. Metode yang digunakan dalam penelitian ini adalah metode deskriptif dengan teknik analisis data kuantitatif. Teknik analisis data kuantitatif digunakan untuk menguraikan data melalui statistik. Teknik pengambilan sampel menggunakan teknik sampling jenuh yaitu teknik penentuan sampel bila semua anggota populasi digunakan sebagai sampel dengan jumlah sampel sebanyak 22 orang, terdiri dari 14 orang PNS dan 8 orang Pegawai Tidak tetap di Kecamatan Malua Kabupaten Enrekang. Teknik pengumpulan data menggunakan observasi, kuesioner dan dokumentasi. Hasil penelitian menunjukkan bahwa peranan Camat terhadap perencanaan pembangunan di Kecamatan Malua Kabupaten Enrekang berjalan dengan baik. Berdasarkan nilai peranan Camat sebesar $90 \%$ yang dikategorikan berperan terhadap perencanaan pembangunan. Berdasarkan nilai komunikasi pemerintahan sebesar $84 \%$ dikategorikan berpengaruh terhadap perencanaan pembangunan. Sedangkan faktor-faktor yang menghambat komunikasi pemerintahan terhadap perencanaan pembangunan yaitu faktor perbedaan latar belakang $82 \%$, faktor bahasa $78 \%$, faktor sikap $84 \%$ dan faktor lingkungan $80 \%$ dikategorikan berpengaruh. Dengan demikian hipotesis yang diajukan terbukti kebenarannya.
\end{abstract}

Kata Kunci : Komunikasi Pemerintahan, Peranan Camat, Perencanaan Pembangunan 


\begin{abstract}
This experimental study is focussed to know the District head's performance and government communication towards the development plan of Malua District, Enrekang Regency. Technical methods of this study is decriptive methods by analytical quantitative data. Quantitative data method use to explain data through statistic report. Technical sampling taken by census sampling, means all 22 sampler are full involved, consist of 14 Civil Servant, 8 Honorary Staff who work at Malua District office, Enrekang Regency. Technical apply for collecting data are observation, quistioner, and documentation. The result of this experiment study that head district has an important role towards to the development plan of Malua District, Enrekang Regency. The District head agreed for $90 \%$ value in deleveloping plan, and reached $84 \%$ rating for communication influences for development plan. While the factors that hamper government communication on development planning are $82 \%$ backround factor, $78 \%$ language factor, $84 \%$ attitude factor and 80 $\%$ environmental factor are categorized as influencing. Conclusion, the hypothetical proposed is proved true.
\end{abstract}

Keywords: Development Plan, District Head Performance, Government Communication 


\section{PENDAHULUAN}

Peranan masyarakat dan swasta dalam pembangunan daerah akan semakin besar dan menentukan. Perlu di sadari tanpa meningkatkan partisipasi masyarakat dan swasta, otonomi akan kehilangan makna dasarnya. Melalui otonomi, pemerintah daerah mempunyai peluang yang lebih besar untuk mendorong dan memberi motivasi pembangunan daerah yang kondusif, sehingga akan munculnya kreasi dan daya inovasi masyarakat yang dapat bersaing dengan daerah lain.

Hal itulah yang ditempuh oleh Pemerintah Kabupaten Enrekang, Provinsi Sulawesi Selatan dalam mendorong setiap potensi yang dimiliki daerahnya, baik itu di bidang perkebunan, pertanian, kehutanan, SDM, aparatur pemerintahan, pendidikan, teknologi dan kemasyarakatan. Dari 12 kecamatan yang ada di Kabupaten Enrekang diharapkan kepada setiap Pemerintah Kecamatan dapat mengidentifikasi potensi-potensi yang ada di wilayahnya masing-masing agar pemerintah kabupaten dapat memetakan seluruh potensi yang ada. Dengan mengetahui seluruh potensi yang ada, diharapkan pemerintah kabupaten dapat mengambil kebijakan yang lebih tepat, guna mendorong percepatan dan pemerataan pembangunan di wilayah Kabupaten Enrekang.

Kenyataannya, bahwa dari 12 kecamatan yang ada di Kabupaten Enrekang, Kecamatan Malua termasuk salah satu kecamatan yang mengalami ketertinggalan pembangunan, dibandingkan dengan kecamatan-kecamatan lain. Hal ini disebabkan karena peran camat selaku kepala wilayah kecamatan belum melakukan komunikasi secara optimal kepada pemerintah daerah kabupaten Enrekang.

Dengan melihat begitu banyak potensi yang ada di Kecamatan Malua, perlu dipikirkan bagaimana cara agar potensi tersebut dapat diberdayakan dan dikembangkan agar dapat mendorong percepatan 
pembangunan di Kecamatan Malua. Pemerintah Kecamatan dalam hal ini Camat selaku kepala pemerintahan tertinggi di wilayah kecamatan dapat mengambil langkah-langkah yang tepat dengan mengajak segenap komponen masyarakat serta pemerintah kabupaten untuk memikirkan bagaimana cara agar Kecamatan Malua dapat mengejar ketertinggalan pembangunannya dibandingkan dengan kecamatan-kecamatan lain.

\section{TINJAUAN PUSTAKA}

\subsection{Pengertian Kepemimpinan}

Menurut Kartini Kartono (2010) (Mustanir and Jaya 2016) (Damis Dadda et al. 2019) (Irwan et al. 2019), Kepemimpinan adalah masalah relasi dan pengaruh antara pemimpin dan yang dipimpin. Kepemimpinan ini bisa berfungsi atas dasar kekuasaan pemimpin untuk mengajak, mempengaruhi, dan menggerakkan orang-orang lain guna melakukan sesuatu, demi pencapaian satu tujuan tertentu.

Jadi, kepemimpinan sebagai ilmu adalah hubungan antara pemimpin dengan yang dipimpin dalam hal ini yang memimpin adalah pemerintah sedangkan yang dipimpin adalah rakyat sendiri, obyek materinya adalah manusia. Kepemimpinan sebagai seni adalah bagaimana seorang pemimpin pemerintahan dengan keahliannya mampu menyelenggarakan pemerintahan secara indah.

\subsection{Peranan Kepemimpinan Camat}

Sebagai perangkat daerah, Camat dalam menjalankan tugasnya mendapat pelimpahan kewenangan dari dan bertanggung jawab kepada bupati/walikota. Tugas Pokok dan Fungsi Kecamatan diatur dalam Peraturan Pemerintah Nomor 19 Tahun 2008. Kecamatan merupakan wilayah kerja tertentu yang dipimpin oleh seorang Camat yang berkedudukan dibawah dan bertanggung jawab 
kepada Kepala Daerah melalui Sekretaris Daerah (Sapri et al. 2019) (Mustanir, Sellang, et al. 2018).

Camat mempunyai tugas pokok melaksanakan kewenangan pemerintahan yang dilimpahkan oleh Kepala Daerah untuk menangani sebagian urusan otonomi daerah dan juga menyelenggarakan tugas umum pemerintahan.

Dalam menyelenggarakan tugas pokoknya, Camat mempunyai fungsi:

1) Pengkoordinasian kegiatan pemberdayaan masyarakat dalam upaya mendorong peran serta masyarakat untuk ikut mensukseskan perencanaan pembangunan dilingkup kecamatan, sekaligus melakukan pembinaan, pengawasan dan evaluasi terhadap berbagai kegiatan pemberdayaan masyarakat di wilayah Kecamatan baik yang dilakukan oleh unit kerja pemerintah maupun swasta. Peran Camat dalam Pembangunan Fisik.

2) Pengkoordinasian upaya penyelenggara ketentraman dan ketertiban umum dan penerapan serta penegakan peraturan perundang-undangan dengan satuan kerja perangkat daerah terkait dan Kepolisian Negara.

3) Pengkoordinasian penyelenggaraan kegiatan pemerintahan di tingkat Kecamatan dengan satuan kerja perangkat daerah dan instansi vertikal agar bersinergi.

4) Pelaporan pelaksanaan tugas secara periodik dan tepat waktu kepada Kepala Derah melalui Sekretaris Daerah.

\subsection{Komunikasi Pemerintahan}

Komunikasi pemerintahan menurut Erliana Hasan (2001) dalam bukunya Komunikasi Pemerintahan, adalah penyampaian ide, program, dan gagasan masyarakat dalam rangka mencapai tujuan negara. Dalam hal ini pemerintah dapat diasumsikan sebagai 
komunikator dan masyarakat sebagai komunikan, namun dalam suasana tertentu bisa sebaliknya masyarakat berada pada posisi sebagai penyampai ide atau gagasan dan pemerintah berada pada posisi mencermati apa yang diinginkan masyarakat. Dalam kondisi tersebut, berarti pemerintah memiliki kewenangan sekaligus bertanggung jawab untuk mempertimbangkan, bahkan untuk merespon keinginan-keinginan tersebut sesuai dengan aturan dan ketentuan yang berlaku.

Pemerintah sebagai pihak pertama, berada di tingkat pusat dan daerah berperan sebagai stakeholders utama dari e-Government. Peranan pemerintah dalam konsorsium (pengusaha yang mengadakan usaha bersama) terkait adalah sebagai pihak yang menentukan tujuan, kebijakan, standar, dan pola kerja sama dari segala yang berkaitan dengan perencanaan, penerapan, dan pengembangan konsep e-Government. Dengan kata lain, pemerintah memiliki kewajiban untuk membentuk sebuah lingkungan yang kondusif agar implementasi sistem e-Government dapat terlaksana dengan baik.

Dalam bukunya, Erliana Hasan (2005:28) menyebutkan bahwa terdapat empat kondisi yang harus dikuasai oleh komunikator dalam menyampaikan pesan, antara lain sebagai berikut: (1) keterampilan, (2) sikap, (3) pengetahuan, dan (4) sistem sosial budaya . Berkenaan dengan keterampilan, Erliana Hasan (2005:89) juga menambahkan, bahwa terdapat beberapa keterampilan yang harus dimiliki komunikator agar komunikasi dapat berjalan secara memuaskan, antara lain: keterampilan mendengarkan, keterampilan bertingkah laku asertif, keterampilan menyelesaikan konflik, keterampilan meyelesaikan masalah secara bersama, keterampilan membaca situasi, keterampilan melakukan persuasi.

Komponen kedua yang harus dikuasai komunikator adalah sikap. Adapun dua diantara faktor-faktor yang menumbuhkan 
hubungan interpersonal yang baik menurut Jalaluddin Rakhmat (1998:129) antara lain sikap suportif dan sikap terbuka. Sedangkan kondisi sistem sosial-budaya yang harus dikuasai oleh komunikator, yaitu yang berkenaan dengan latar belakang pendidikan dan norma yang berlaku di lingkungan masyarakat selaku komunikan. Hal ini sejalan dengan apa yang diungkapkan oleh Millet J.J (dalam Erliana Hasan,2005:108) bahwa dalam menjalankan aktivitas penerangan dan sebagainya digunakan sistem komunikasi yang cocok yakni tergantung pada dua faktor. Salah satunya adalah keadaan dari yang menerima komunikasi.

Berkaitan dengan isi pesan, dijelaskan pula oleh Erliana Hasan (2005:58), bahwa pesan komunikasi terdiri dari pikiran sebagai isi pesan dan lambang sebagai media primer sebagai pembawa pikiran kepada komunikan. Sehingga dapat disimpulkan bahwa pesan yang disampaikan oleh Pemerintah Kecamatan sesungguhnya dipengaruhi oleh komponen pertama pada penjelasan sebelumnya. Karena isi pesan itu sendiri merupakan pikiran yang diungkapkan oleh komunikator. Dan pikiran itulah yang sebenarnya terbentuk jika komponen pertama telah dipenuhi oleh komunikator, yakni yang berkaitan dengan sikap, keterampilan, pengetahuan, dan sistem sosial-budaya. Sehingga dengan penguasaan keempat kondisi itulah, yang akan mempengaruhi komunikator dalam berpikir yang kemudian dikeluarkan melalui pesan yang disampaikan (Latif et al. 2019) (Mustanir 2019) (Mustanir 2015) (Mustanir, n.d.) (Mustanir 2017a) (Mustanir 2018a) (Mustanir 2017b) (Mustanir 2018b) (Ramadhan and Mustanir 2017) (Razak et al. 2018) (Uceng, Ali, et al. 2019).

\subsection{Perencanaan Pembangunan}

Menurut Tjokroamidjojo dalam elisa.ugm.ac.id (2014:1) perencanaan memiliki pengertian dalam arti luas sebagai suatu 
proses mempersiapkan secara sistematis kegiatan-kegiatan yang akan dilakukan untuk mencapai tujuan-tujuan tertentu. Perencanaan merupakan suatu cara bagaimana seorang atau sekelompok manusia mencapai tujuan sebaik-baiknya dengan sumber-sumber yang ada supaya lebih efisien dan efektif. Selain hal diatas, perencanaan juga menjadi suatu penentu tujuan yang akan dicapai atau yang akan dilakukan, bagaimana, bilamana dan oleh siapa. Sjafrizal (2014 : 24) perencanaan pembangunan adalah cara atau teknik untuk mencapai tujuan pembangunan secara tepat, terarah dan efisien sesuai dengan kondisi daerah yang bersangkutan.

Musrenbang adalah forum-forum multi-pihak terbuka yang secara bersama mengidentifikasi dan menentukan prioritas kebijakan pembangunan masyarakat. Musyawarah perencanaan pembangunan (musrenbang) Kecamatan adalah forum musyawarah tahunan para pemangku kepentingan (stakeholders) Kecamatan untuk menyepakati rencana kerja Kecamatan tahun anggaran berikutnya (tim kerja buku panduan penyelenggaraan Musrenbang, 2008:3) (Uceng, Erfina, et al. 2019) (Uceng, Ali, et al. 2019) (Mustanir, Yasin, et al. 2018).

Musrenbang yang menurut Sumpeno (2008:28) (Mustanir and Yasin 2018) (Mustanir, Sellang, et al. 2018) (Mustanir and Rusdi. Muhammad 2019) (Mustanir and Razak 2017) (Mustanir and Lubis 2017) (Mustanir, Justira, et al. 2018) (Mustanir and Jusman 2016) (Mustanir, Dema, et al. 2018) (Mustanir and Darmiah 2016) (Mustanir, Ahmad; Barisan, Barisan; Hamid 2017) (Mustanir, Ali, and Yasin 2018) (Mustanir, Abadi, and Nasri 2016) (Mustanir, Ahmad; Abadi 2016) (Mustanir 2016) (Akhmad, Mustanir, and Ramadhan 2018) merupakan perencanaan pembangunan bersama masyarakat adalah merupakan panduan atau model pembangunan Kecamatan yang menitikberatkan pada peran serta masyarakat dalam keseluruhan proses pembangunan. Pendekatan ini dilandasi oleh 
nilai-nilai dan semangat gotong-royong yang telah mengakar dalam budaya masyarakat Indonesia. Gotong-royong bertumpu pada keyakinan bahwa setiap warga masyarakat memiliki hak untuk memutuskan dan merencanakan apa yang terbaik bagi diri dan lingkungan serta cara terbaik dalam upaya mewujudkannya.

\subsection{Faktor-Faktor yang menghambat Komunikasi Pemerintahan} terhadap Perencanaan Pembangunan

Meskipun komunikasi tampaknya sederhana, tetapi untuk mendapatkan komunikasi yang efektif seringkali banyak hambatan, walaupun faktor situasi dan kondisi turut beperan, tetapi faktor manusia yang paling banyak berperan. Karena komunikasi sebagai suatu proses interaksi, maka faktor manusia memainkan peran yang sangat penting dalam pencapaian komunikasi yang efektif (Erliana Hasan 2005:91)

Berikut ini uraian singkat beberapa faktor yang menghambat proses komunikasi :

1) Perbedaan latar belakang; Setiap orang ingin diperlakukan sebagai pribadi, dan memang setiap orang berbeda, berkaitan dengan perbedaan itu merupakan tanggungjawab komunikator (pengirim pesan) untuk mengenal perbedaan tersebut dan menyesuaikan isi pesan yang hendak disampaikan dengan kondisi penerima pesan secara tepat, dan memilih media serta saluran komunikasi sesuai agar respon yang diharapkan dapat tercapai. Perbedaan yang mungkin dapat menimbulkan kesalahan dalam komunikasi antara lain:
a. Perbedaan persepsi
b. Perbedaan Pengalaman dan latar belakang
c. Sikap praduga/stereotip 
2) Faktor bahasa; Bahasa yang digunakan seseorang verbal maupun nonverbal (bahasa tubuh) ikut berpengaruh dalam proses komunikasi antara lain:

a. Perbedaan arti kata

b. Penggunaan istilah atau bahasa tertentu

c. Komunikasi nonverbal

3) Sikap pada waktu berkomunikasi; Hal ini ikut berperan, bahkan sering menjadi faktor utama, sikap-sikap seseorang yang dapat meghambat komunikasi tersebut antara lain :

a. Mendengar hanya apa yang ingin kita dengar

b. Mengadakan penilaian terhadap pembicara

c. Sibuk mempersiapkan jawaban

d. Bukan pendengar yang baik

e. Pengaruh faktor emosi

f. Kurang percaya diri

g. Gaya/cara bicara dan nada suara

4) Faktor lingkungan; Lingkungan dan kondisi tempat kita berkomunikasi juga ikut menetukan proses maupun hasil komunikasi tersebut. Hal hal yang berpengaruh antara lain:
a. Faktor tempat
b. Faktor situasi/waktu

\section{METODE PENELITIAN}

Metode penelitian yang digunakan dalam penelitian ini adalah metode penelitian kuantitatif, di mana penelitian yang dilakukan bersifat deskriptif. Jamaluddin Ahmad (2015) memberikan pengertian penelitian adalah rencana atau strategi yang digunakan untuk menjawab masalah penelitian (menguji hipotesis) dan mengontrol variabel atau fokus penelitian. Dalam penelitian ini menggunakan sampling jenuh yaitu teknik penentuan sampel bila semua anggota populasi digunakan sebagai sampel (Sugiyono, 2016:85) . Dengan 
memperhatikan hal di atas, maka sampel dalam penelitian ini adalah seluruh aparat pemerintah kecamatan.

Teknik pengumpulan data dalam penelitian ini adalah Observasi, yaitu pengumpulan data dengan cara mengadakan pengamatan langsung terhadap objek penelitian. Kuisioner yaitu pengumpulan data dengan memberikan sejumlah pertanyaan/pernyataan berkaitan dengan objek yang diteliti. Dokumentasi yaitu sejumlah besar fakta dan data tersimpan dalam bahan yang berbentuk dokumentasi. Teknik pengumpulan data ini adalah melalui dokumen atau peninggalan tertulis terutama berupa arsip-arsip dan sebagainya yang relevan dengan masalah yang sedang diteliti.

Data yang dikumpulkan akan di analisis secara deskriptif kuantitatif. Analisis tersebut di dukung oleh tabel frekwensi pada beberapa variable pendukung yang di jadikan indikator dalam penelitian ini. Analisis data untuk memperoleh gambaran tentang kondisi setiap variable secara tunggal dilakukan dengan tabel frekwensi dengan analisis deskripsi dengan menentukan rentang skala yaitu skala Likert (Sugiyono, 2016:93)

\section{PEMBAHASAN}

Dalam pembahasan dan pengolahan data pada bab ini, peneliti menggunakan rumus sebagai berikut :

Rata-rata Skor $\sum \frac{F \cdot X}{N}$ ( Hasan. I : 2005)

Keterangan :

$\Sigma$ : rata-rata skor

$F$ : jumlah jawaban responden setiap item

$X:$ skor item $a=4, b=3, c=2$, dan $d=1$

$\mathrm{N}$ : total jawaban responden seluruh item 
4.1 Indikator Peranan Camat

Tabel 1. Rekapitulasi Tanggapan Responden Mengenai Indikator Peranan Camat

\begin{tabular}{|c|c|c|c|}
\hline No & Tanggapan responden & $\begin{array}{l}\text { Rata- } \\
\text { rata } \\
\text { rkor }\end{array}$ & $\begin{array}{l}\text { Rata- Rata } \\
\text { Presentase }\end{array}$ \\
\hline 1 & $\begin{array}{lr}\text { Peranan Camat } & \text { dalam } \\
\text { pengkoordinasian } & \text { kegiatan } \\
\text { pemberdayaan masyarakat } & \text { dalam } \\
\text { perencanaan Pembangunan } & \end{array}$ & 3,68 & 92 \\
\hline 2 & $\begin{array}{l}\text { Peranan Camat dalam } \\
\text { pengkoordinasian } \\
\text { penyelenggaraan ketentraman dan } \\
\text { ketertiban umum dalam perencanaan } \\
\text { Pembangunan }\end{array}$ & 3,63 & 91 \\
\hline 3 & $\begin{array}{l}\text { Peranan Camat melakukan } \\
\text { pengkoordinasian penyelenggaraan } \\
\text { kegiatan pemerintahan di tingkat } \\
\text { Kecamatan dengan satuan kerja } \\
\text { perangkat daerah dan instansi vertikal } \\
\text { agar bersinergi dalam perencanaan } \\
\text { Pembangunan }\end{array}$ & 3,59 & 90 \\
\hline 4 & $\begin{array}{l}\text { Peranan Camat melakukan Pelaporan } \\
\text { pelaksanaan tugas secara periodik } \\
\text { dan tepat waktu kepada Kepala } \\
\text { Derah melalui Sekretaris Daerah } \\
\text { dalam perencanaan Pembangunan }\end{array}$ & 3,63 & 91 \\
\hline & Jumlah & 3,63 & 90 \\
\hline
\end{tabular}

Sumber : Hasil Olahan data rekapitulasi kuisioner

Berdasarkan Tabel di atas dapat dijelaskan bahwa Masyarakat Kecamatan yang sebagai responden memberikan tanggapan bahwa dalam rekapitulasi indikator peranan Camat dengan nilai $\mathbf{9 0} \%$ yang berdasarkan berbagai pertanyaan sesuai dengan indikator diatas. 
4.2 Indikator Komunikasi Pemerintahan Terhadap Perencanaan Pembangunan

Tabel 2. Rekapitulasi Tanggapan Responden Mengenai Indikator Komunikasi Pemerintahan

\begin{tabular}{|c|c|c|c|}
\hline No & \multicolumn{1}{|c|}{ Tanggapan responden } & $\begin{array}{c}\text { Rata- } \\
\text { rata } \\
\text { Skor }\end{array}$ & $\begin{array}{c}\text { Rata- Rata } \\
\text { Peresentase }\end{array}$ \\
\hline 1 & $\begin{array}{l}\text { Hambatan dalam proses komunikasi } \\
\text { pemerintahan yaitu perbedaan latar } \\
\text { belakang dalam perencanaan } \\
\text { Pembangunan }\end{array}$ & 3,27 & 82 \\
\hline 2 & $\begin{array}{l}\text { Faktor bahasa yang menghambat } \\
\text { proses komunikasi adalah penggunaan } \\
\text { istilah atau bahasa tertentu dalam } \\
\text { perencanaan Pembangunan }\end{array}$ & 3,13 & 78 \\
\hline 3 & $\begin{array}{l}\text { Sikap pada waktu berkomunikasi yang } \\
\text { menghambat proses komunikasi } \\
\text { adalah adanya tidak percaya diri dalam } \\
\text { perencanaan Pembangunan }\end{array}$ & 3,36 & 84 \\
\hline 4 & $\begin{array}{l}\text { Faktor lingkungan juga dapat } \\
\text { menghambat proses komunikasi yaitu } \\
\text { tempat dan situasi waktu dalam } \\
\text { perencanaan Pembangunan }\end{array}$ & 3,22 & 80 \\
\hline \multicolumn{2}{|c|}{ Jumlah } & 3,24 & 84 \\
\hline
\end{tabular}

Sumber : Hasil Olahan data rekapitulasi kusioner

Berdasarkan tabel di atas dapat dijelaskan bahwa Masyarakat Kecamatan yang sebagai responden memberikan tanggapan bahwa dalam rekapitulasi indikator komunikasi pemerintahan dengan nilai $84 \%$ yang berdasarkan berbagai pertanyaan sesuai dengan indikator diatas. 
4.3 Indikator Perencanaan Pembangunan

Tabel 3.Rekapitulasi Tanggapan Responden Mengenai Indikator Perencanaan Pembangunan

\begin{tabular}{|c|c|c|c|}
\hline No & Tanggapan responden & $\begin{array}{c}\text { Rata- } \\
\text { rata } \\
\text { Skor }\end{array}$ & $\begin{array}{c}\text { Rata- Rata } \\
\text { Peresentase }\end{array}$ \\
\hline 1 & $\begin{array}{l}\text { Perencanaan pembangunan dalam arti } \\
\text { luas adalah suatu proses } \\
\text { mempersiapkan secara sistematis } \\
\text { kegiatan-kegiatan yang akan dilakukan } \\
\text { untuk mencapai tujuan-tujuan tertentu }\end{array}$ & 3,5 & 87 \\
\hline 2 & $\begin{array}{l}\text { Perencanaan merupakan suatu cara } \\
\text { bagaimana seorang atau sekelompok } \\
\text { manusia mencapai tujuan sebaik- } \\
\text { baiknya dengan sumber-sumber yang } \\
\text { ada supaya lebih efisien dan efektif }\end{array}$ & 3,5 & 87 \\
\hline 3 & $\begin{array}{l}\text { Perencanaan juga menjadi suatu } \\
\text { penentu tujuan yang akan dicapai atau } \\
\text { yang akan dilakukan }\end{array}$ & 3,59 & 90 \\
\hline \multicolumn{1}{|c|}{ Jumlah } & 3,53 & 87 \\
\hline
\end{tabular}

Sumber : Hasil Olahan data rekapitulasi kusioner

Berdasarkan Tabel di atas dapat dijelaskan bahwa Masyarakat desa yang sebagai responden memberikan tanggapan bahwa dalam rekapitulasi indikator perencanaan pembangunan dengan nilai $87 \%$ yang berdasarkan berbagai pertanyaan sesuai dengan indikator diatas

\section{KESIMPULAN.}

Berdasarkan uraian-uraian serta pembahasan pada bab terdahulu maka penulis memberi kesimpulan sebagai berikut :

1) Peranan Camat terhadap perencanaan pembangunan sebesar $90 \%$ atau di kategorikan ( baik ) berperan.

2) Komunikasi pemerintahan terhadap perencanaan pembangunan $84 \%$ atau dikategorikan ( Baik ) / berpengaruh. 
3) Sedangkan faktor-faktor yang menghambat komunikasi pemerintahan terhadap perencanaan pembangunan yaitu faktor perbedaan latar belakang $82 \%$, faktor bahasa $78 \%$, faktor sikap $84 \%$ dan faktor lingkungan dikategorikan berpengaruh

\section{DAFTAR PUSTAKA}

Akhmad, Israwaty, Ahmad Mustanir, and Muhammad Rohady Ramadhan. 2018. "Pengaruh Pemanfaatan Tekhnologi Informasi Dan Pengawasan Keuangan Daerah Terhadap Kualitas Laporan Keuangan Kabupaten Enrekang." In Prosiding Konferensi Nasional Ke-7 Asosiasi Program Pascasarjana Perguruan Tinggi Muhammadiyah Aisyiyah (APPPTMA). Jilid 2. Sosial Politik Dan Ekonomi, 89-103. http://asosiasipascaptm.or.id/index.php/publikasi/konferensi-appptmke-7-meningkatkan-kualitas-dan-kuantitas-jurnal-ilmiah.

Damis Dadda, Andi, Ahmad Mustanir, Andi Nilwana, and Jamaluddin Ahmad. 2019. "Pengaruh Kepemimpinan Lurah Perempuan Terhadap Stabilitas Kamtibmas Di Kelurahan Rappang Kabupaten Sidenreng Rappang." In Konferensi Nasional Ke-8 Asosiasi Program Pascasarjana Perguruan Tinggi Muhammadiyah Aisyiyah (APPPTMA), 378-83. Medan: Program Pascasarjana Universitas Muhammadiyah Yogyakarta. http://asosiasipascaptm.or.id/index.php/publikasi/prosiding-konferensinasional-appptma-ke-8.

Hasan Erliana, 2005, Komunikasi Pemerintahan, Bandung: Refika Aditama.

Hasan. I. 2005 Pokok-pokok materi statistik I. Edisi kedua. Jakarta : PT. Bumi Aksara

Irwan, Irwan, Adam Latif, Sofyan Sofyan, Ahmad Mustanir, and Fatimah Fatimah. 2019. "Gaya Kepemimpinan, Kinerja Aparatur Sipil Negara Dan Partisipasi Masyarakat Terhadap Pembangunan Di Kecamatan Kulo Kabupaten Sidenreng Rappang." MODERAT: Jurnal IImiah IImu Pemerintahan Universitas Galuh Ciamis 5 (1): 32-43. https://jurnal.unigal.ac.id/index.php/moderat/article/view/1900.

Kartini Kartono. 2010. Pemimpin Dan Kepemimpinan: Apakah 
Jurnal IImiah Clean Government

ISSN: E-2620-3014

: P-2614-7742

Vol. 2, No. 2, Juni 2019

Kepemimpinan Abnormal Itu. Rajawali Press. Jakarta.

Latif, Adam, Irwan Irwan, Muhammad Rusdi, Ahmad Mustanir, and Muh Sutrisno. 2019. "Partisipasi Masyarakat Dalam Pembangunan Infrastruktur Di Desa Timoreng Panua Kecamatan Panca Rijang Kabupaten Sidenreng Rappang." MODERAT: Jurnal IImiah Ilmu Pemerintahan Universitas Galuh Ciamis 5 (1): 1-15. https://jurnal.unigal.ac.id/index.php/moderat/article/view/1898.

Mustanir, Ahmad; Abadi, Partisan. 2016. "PARTISIPASI MASYARAKAT DALAM MUSYAWARAH RENCANA PEMBANGUNAN DI KELURAHAN KANYUARA KECAMATAN WATANG SIDENRENG KABUPATEN SIDENRENG RAPPANG." Jurnal Politik Profetik 5 (2): 247-61. http://journal.uinalauddin.ac.id/index.php/jpp/article/viewFile/4347/3986.

Mustanir, Ahmad; Barisan, Barisan; Hamid, Hariyanti. 2017. "Participatory Rural Appraisal As The Participatory Planning Method Of Development Planning." In Indonesian Association for Public Administration (IAPA) International Conference Towards Open Government: Finding the Whole Government Approach, edited by Philipus Keban Nanang Haryono, Agie Nugroho Soegiono, Putu Aditya Ferdy Ariawantara, 77-84. Surabaya: The Faculty Of Social And Political Science Universitas Airlangga. http://conference.unair.ac.id/index.php/IAPA/iapa2017.

Mustanir, Ahmad. n.d. "Pemberdayaan Masyarakat Kewirausahaan." https://www.researchgate.net/publication/331311483_Pemberdayaan_ Masyarakat_Kewirausahaan.

2015. "Pemberdayaan Masyarakat Berbasis Bina Desa."

2016. "Perencanaan Mewujudkan Kehidupan Pemerintahan Dan Sosial Yang Islami Di Desa Tonrong Rijang Kabupaten Sidenreng Rappang." In Seminar Nasional, Reformasi Dan Inovasi Tata Kelola Pemerintahan, edited by Budiman, Rita Kalalinggi, Burhanudin, and Jauchar B, 289-307. Samarinda: FISIP UNIVERSITAS MULAWARMAN.

https://www.researchgate.net/publication/330101808_Perencanaan_M ewujudkan_Kehidupan_Pemerintahan_dan_Sosial_Yang_Islami_di_D esa_Tonrong_Rijang_Kabupaten_Sidenreng_Rappang. 

—_ 2017a. "Deskripsi Tentang Keamanan Di Gedung Dan Jalanan Kota Kuala Lumpur." Kuala Lumpur. https://www.researchgate.net/publication/331064740_Deskripsi_Tenta ng_Keamanan_Di_Gedung_dan_Jalanan_Kota_Kuala_Lumpur.

2017b. "Pemberdayaan Badan Usaha Milik Desa Melalui Kelompok Ekonomi Kewirausahaan Secara Partisipatif." Rappang. https://www.researchgate.net/publication/331065123_Pemberdayaan_ Badan_Usaha_Milik_Desa_Melalui_Kelompok_Ekonomi_Kewirausaha an_Secara_Partisipatif.

. 2018a. "Pemanfaatan Teknologi Informasi Dalam Optimalisasi Pelayanan Publik Dan Potensi Desa Sereang." Rappang. https://www.researchgate.net/publication/331064206_Pemanfaatan_T eknologi_Informasi_Dalam_Optimalisasi_Pelayanan_Publik_dan_Pote nsi_Desa_Sereang.

2018b. "Pemberdayaan Perempuan Anggota Badan Usaha Milik Desa Dengan Pemanfaatan Lahan Kebun Bibit Desa." Rappang. https://www.researchgate.net/publication/331071158_Pemberdayaan_ Perempuan_Anggota_Badan_Usaha_Milik_Desa_dengan_Pemanfaat an_Lahan_Kebun_Bibit_Desa.

- 2019. "Referensi Article Partisipasi Masyarakat Perencanaan Pembangunan Dan Pemberdayaan Masyarakat," no. May.

Mustanir, Ahmad, Partisan Abadi, and A Nasri. 2016. "Participation of Ethnic Community Towani Tolotang in Deliberation of Development Plan." In International Conference on Ethics in Governance (ICONEG 2016), 84:356 - 359. Makassar: Atlantis Press. https://doi.org/10.2991/iconeg-16.2017.79.

Mustanir, Ahmad, Akhwan Ali, and Akhmad Yasin. 2018. "Transect on Participatory Development Planning in Sidenreng Rappang Regency." In IOP Conference Series: Earth and Environmental Science. Maka.

Mustanir, Ahmad, and Darmiah Darmiah. 2016. "IMPLEMENTASI KEBIJAKAN DANA DESA DAN PARTISIPASI MASYARAKAT DALAM PEMBANGUNAN DI DESA TETEAJI KECAMATAN TELLU LIMPOE KABUPATEN SIDENRENG RAPPANG." Jurnal Politik Profetik 4 (2): 225-38.

http://journal.uin- 
Jurnal IImiah Clean Government

ISSN: E-2620-3014

: P-2614-7742

Vol. 2, No. 2, Juni 2019

alauddin.ac.id/index.php/jpp/article/view/2749.

Mustanir, Ahmad, Herman Dema, Haeruddin Syarifuddin, Kiki Meity, and Sri Wulandari. 2018. "Pengaruh Motivasi Dan Partisipasi Masyarakat Terhadap Pembangunan Di Kelurahan Lalebata Kecamatan Panca Rijang Kabupaten Sidenreng Rappang." Jurnal IImiah Clean $\begin{array}{llll}\text { Government } & \text { (JCG) } & 2 & \text { (1): 27-39. }\end{array}$ http://lonsuit.unismuhluwuk.ac.id/index.php/clean/article/view/212.

Mustanir, Ahmad, and Irfan Jaya. 2016. "PENGARUH KEPEMIMPINAN DAN BUDAYA POLITIK TERHADAP PERILAKU PEMILIH TOWANI TOLOTANG DI KECAMATAN MARITENGNGAE KABUPATEN SIDENRENG RAPPANG." Jurnal Politik Profetik 4 (1): 84-97. http://journal.uin-alauddin.ac.id/index.php/jpp/article/view/2741\#.

Mustanir, Ahmad, and Jusman. 2016. "IMPLEMENTASI KEBIJAKAN DAN EFEKTIVITAS PENGELOLAAN TERHADAP PENERIMAAN RETRIBUSI DI PASAR LANCIRANG KECAMATAN PITU RIAWA KABUPATEN SIDENRENG RAPPANG." Jurnal IImiah Akmen 13 (3): 542-58.

https://e-jurnal.stienobelindonesia.ac.id/index.php/akmen/article/view/69.

Mustanir, Ahmad, Nur Justira, Kamaruddin Sellang, and Andi Ilham Muchtar. 2018. "Democratic Model On Decision-Making At Deliberations Of Development Planning." International Conference on Government Leadership and Social Science (ICOGLASS). Demanding Governance Accountability and Promoting Democratic Leadership for Public Welfare Achievement, 110 - 115. https://www.researchgate.net/publication/330090538_Democratic_Mo del_On_Decision-

Making_At_Deliberations_Of_Development_Planning.

Mustanir, Ahmad, and Sandi Lubis. 2017. "Participatory Rural Appraisal in Deliberations of Development Planning." In International Conference On Democracy, Accountability, and Governance (ICODAG 2017), 163:316-19. Pekanbaru: Atlantis Press. https://doi.org/10.2991/icodag-17.2017.60.

Mustanir, Ahmad, and M Rais Rahmat Razak. 2017. "Nilai Sosial Budaya Pada Partisipasi Masyarakat Etnik Towani Tolotang Dalam Musyawarah Rencana Pembangunan." In Prosiding Konferensi 
Nasional Ke-6 Asosiasi Program Pascasarjana Perguruan Tinggi Muhammadiyah Aisyiyah (APPPTMA), 1-7. Pare Pare: Program Pascasarjana Universitas Muhammadiyah Yogyakarta. http://asosiasipascaptm.or.id/index.php/publikasi/prosiding-konferensinasional-appptma-ke-6.

Mustanir, Ahmad, and Rusdi. Muhammad. 2019. "Participatory Rural Appraisal (PRA) Sebagai Sarana Dakwah Muhammadiyah Pada Perencanaan Pembangunan Di Kabupaten Sidenreng Rappang." In Konferensi Nasional Ke-8 Asosiasi Program Pascasarjana Perguruan Tinggi Muhammadiyah Aisyiyah (APPPTMA), 378-83. Medan: Penerbit Program Pascasarjana Universitas Muhammadiyah Yogyakarta.

http://asosiasipascaptm.or.id/index.php/publikasi/prosiding-konferensinasional-appptma-ke-8.

Mustanir, Ahmad, Kamaruddin Sellang, Akhwan Ali, Madaling Madaling, and Mutmainna Mutmainna. 2018. "PERANAN APARATUR PEMERINTAH DESA DAN PARTISIPASI MASYARAKAT DALAM MUSYAWARAH PERENCANAAN PEMBANGUNAN DI DESA TONRONGNGE KECAMATAN BARANTI KABUPATEN SIDENRENG RAPPANG." Jurnal IImiah Clean Government (JCG) 2 (1): 67-84. http://lonsuit.unismuhluwuk.ac.id/index.php/clean/article/view/213.

Mustanir, Ahmad, and Akhmad Yasin. 2018. "Community Participation in Transect on Development Planning." Jurnal IImiah IImu Administrasi Publik: Jurnal Pemikiran Dan Penelitian Administrasi Publik (JIAP) 8 (2): 137-46. https://doi.org/https://doi.org/10.26858/jiap.v8i2.7994.

Mustanir, Ahmad, Akhmad Yasin, Irwan Irwan, and Muhammad Rusdi. 2018. "Potret Irisan Bumi Desa Tonrong Rijang Dalam Transect Pada Perencanaan Pembangunan Partisipatif." MODERAT: Jurnal IImiah llmu Pemerintahan $\quad 4 \quad$ (4): 14 .14. https://jurnal.unigal.ac.id/index.php/moderat/article/view/1775.

Rakhmat, Jalaluddin, 1998, Psikologi Komunikasi, Bandung: Remaja Rosdakarya

Ramadhan, Muhammad Rohady, and Ahmad Mustanir. 2017. "Sidenreng Rappang Versus Masyarakat Ekonomi Asean." In . http://jksg.umy.ac.id/wp-content/uploads/2017/08/Proceding-The-2nd- 
Journal-of-Government-and-Politics-2017.compressed.pdf.

Razak, Muhammad Rais Rahmat, Mansyur Dahong, Jamaluddin Ahmad, Herman Dema, and Ahmad Mustanir. 2018. "The Effect of Siri's Marriage on Government Administration." International Journal of Sciences: Basic and Applied Research (IJSBAR) 42 (3): 171-84. http://gssrr.org/index.php?journal=JournalOfBasicAndApplied\&page $=\mathrm{a}$ rticle\&op=view\&path\%5B\%5D=9484.

Sapri, Sapri, Ahmad Mustanir, Monalisa Ibrahim, Andi Astinah Adnan, and Wirfandi Wirfandi. 2019. "Peranan Camat Dan Partisipasi Masyarakat Dalam Musyawarah Perencanaan Pembangunan Di Kecamatan Enrekang Kabupaten Enrekang." MODERAT: Jurnal IImiah IImu Pemerintahan 5 33-48. https://jurnal.unigal.ac.id/index.php/moderat/article/view/2127.

Sjafrizal. 2014. Perencanaan Pembangunan Daerah Dalam Era Otonomi. Jakarta: Rajawali Pers

Sugiyono, 2016, Metode Penelitian Kuantitatif, Kualitatif dan $R \& D$, Bandung: Alfabeta.

Sumpeno, Wahyudin. Perencanaan Desa Terpadu (Panduan Perencanaan Pembangunan Berbasis Masyarakat). Jakarta : CRS Indonesia.

Tim Kerja. 2008. Buku Panduan Penyelenggaraan Musrenbang.

Tjokroamidjojo. 2014 dalam elisa. Ugm.ac.id

Uceng, Andi, Akhwan Ali, Ahmad Mustanir, and Nirmawati Nirmawati. 2019. "Analisis Tingkat Partisipasi Masyarakat Terhadap Pembangunan Sumber Daya Manusia Di Desa Cemba Kecamatan Enrekang Kabupaten Enrekang." Jurnal MODERAT 5 (2): 1-17. https://jurnal.unigal.ac.id/index.php/moderat/article/view/2125.

Uceng, Andi, Erfina Erfina, Ahmad Mustanir, and Sukri Sukri. 2019. "Partisipasi Masyarakat Dalam Musyawarah Perencanaan Pembangunan Di Desa Betao Riase Kecamatan Pitu Riawa Kabupaten Sidenreng Rappang." MODERAT: Jurnal IImiah IImu Pemerintahan 
Jurnal IImiah Clean Government

ISSN: E-2620-3014

: P-2614-7742

Vol. 2, No. 2, Juni 2019

https://jurnal.unigal.ac.id/index.php/moderat/article/view/2126. 